\title{
KONSTMUSEET SOM METAFOR: OM MUSEET SOM TIDSANGIVARE OCH OM UTSTÄLLNINGARNA SOM TVIVELAKTIGA VERKTYG
}

Beate Sydhoff

Knappast någon typ av offentliga byggnader $i$ vår tid är omgivna med så mycket forväntningar och överdrivna förhoppningar som museibyggnaderna - när de ska byggas om eller nyproduceras - och särskilt då konstmuseerna. Det går att peka på oräkneliga exempel $i$ Europa och USA som visar museets växande betydelse som tecken for sin tid, och detta i stora delar av världen idag.

Ett av de tidigaste och också märkligaste museerna av detta slag är det antropologiska museet i Mexico City, som byggdes för mer än trettio år sedan. Dess «språkliga” form, som blev en symbol för det mexikanska folkets många heroiska kulturer, anknöt visserligen till en nationalistisk museitradition, men museibyggnaden blev på samma gång till ett konstnärligt tecken för mycket djupare andliga krafter. Inte minst utställningsinstallationerna byggde upp sceniska stämningar som ljusmässigt tycktes lånade från operans värld. Plötsligt blev det tydligt att museet var mer än en samling objekt ordnade i kronologiska strukturer. Museet var en röst ur historien riktad mot framtiden, ett sökinstrument för det kommande, men också en iscensättning av ett medvetande om alla kulturers förvandlingar och slutliga upplösning.

Det antropologiska museet i Mexico
City angav en ny potential för museet som pedagogiskt och andligt verktyg, och detta skedde ungefär samtidigt som den nya massmediabaserade konsten under början av sextiotalet började spränga de traditionella museirummen. Därefter har följt flera decennier av ständigt ökande intresse för konstmuseets arkitektur och språk, och den ena spektakulära byggnaden efter den andra har kommit till såväl i Europa som i Nya Världen. Även äldre byggnader som Louvren i Paris har berikats med utbyggnader, som markerar konstmuseets nya metaforiska roll i stadsplaneringen och i det kulturella världssamfundet.

\section{MUSEETS NYA ROLLER}

Under denna period, ca 1960 - 1990, har konstmuseets roll förändrats mycket radikalt. Något generaliserat kan man urskilja 
126 en rörelse från representativitet till subjektivitet, dvs. museet strävar mindre efter att vara representativt för ett visst konstliv för att istället välja sin egen inriktning. Samtidigt har man i den arkitektoniska utformningen gått från en objektiv arkitektur mot en individualistisk form, dvs. mot en form som envetet markerar sin egen "språklighet» mer än att vara ett neutralt skal kring en konstsamling. På detta sätt kan museets nya roll ses mer som en metafor än en renodlad funktion.

Samtidigt har samlingarna inne i konstmuseet ändrat karaktär och stora delar av dem avlägsnat sig från att vara delar av regelrätta utställningar till att bli installationer. I detta ligger då också att museet också avlägsnar sig från att vara distributör av ett budskap eller ett material till att vara producent i nära samverkan med konstnären. Därvid faller också museets syn på sig själv som opartiskt i förhållandet till kulturlivet, vilket betyder att man är beredd att ta på sig en mer ideologisk roll i sin samtid.

I en tidigare artikel i Nordisk Museologi (1995:1) beskrev jag hur konstmuseet i vår tid alltmer tagit på sig rollen som andligt centrum och även markerat detta i den nya arkitekturen. Genom att konsten fokuserat sig så starkt på frågor som har med existensen och sönderfallet att göra, blir museets utställningar mycket ofta till mänskligt utlämnande sammanställningar som tillspetsat pekar mot icke-materiella situationer.

Kyrkobyggnader tillhör dock idag inte den arkitektur som förmår inspirera till nytänkande i museisammanhang. Därför har det nya "andliga» konstmuseet hämtat sin inspiration från helt andra håll. Det slog mig med full kraft för några veckor sedan, när jag satt i Barcelonas stora flygterminal av glas (av Ricardo Bofill), hur nära den i själva verket stod den nya museiarkitekturen, bl.a. det nya moderna konstmuseet i samma stad (av Richard Meyer) och många andra hisnande glastempel. När man i framtiden ser tillbaka på vår tids arkitektur kommer utan tvivel just flygplatsarkitekturen och museibyggnaderna att vara den form som det sena 1900talet kommer att karaktäriseras genom.

\section{DET MOTSÄGELSEFULLA MUSEET}

Analogin mellan konstmuseet och flygterminalen beror inte enbart av den yttre formen. I båda fallen handlar det om ett djupare symbolspråk, som kan sägas bygga på ett behov av att förmedla en känsla av immaterialitet. Konstmuseet, som det alltmer ser sin roll, ska visa fram sin tids andliga formspråk och inbjuder därvid till en resa i tiden och medvetandet. Flygplatsbyggnaden inbjuder också till en resa som kan upplevas som relativt immateriell såtillvida att den äger rum i luftrummet och förbereds i en miljö präglad av overklighet och tidsupplösning. Resan genom olika tidszoner gör att resenären förlorar sin fasta upplevelse av tiden och rummet, något som stämmer väl också med den nya konstens markering av relativiteten i rumsupplevelsen och med dess ovilja att fixera sina undersökningar i förblivande former.

Behovet av att skapa nya konstmuseer i vår tid är förbundet med ett antal märkliga motsägelser. Den första av dem hänger samman med konsten de har som uppdrag 


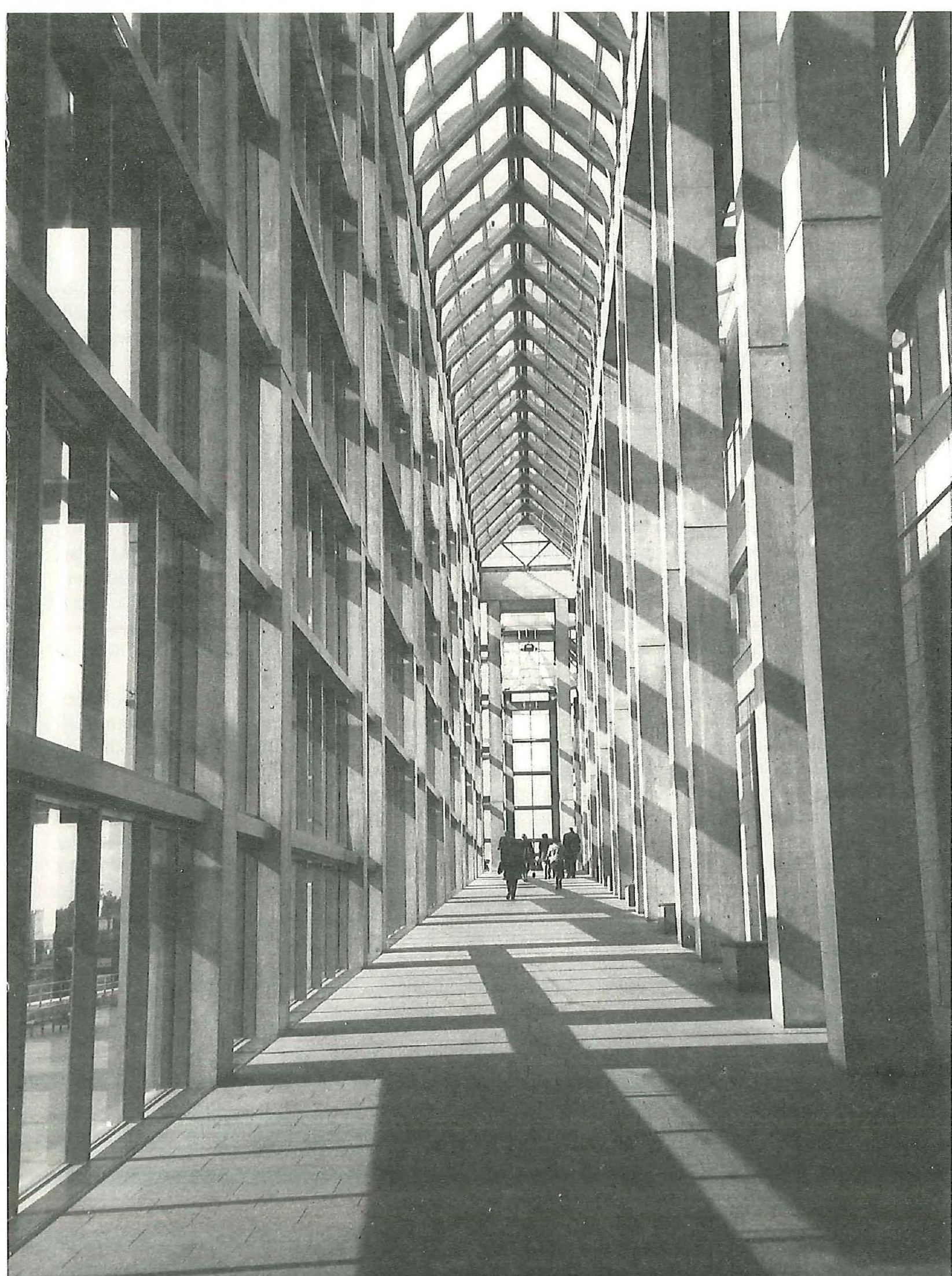


128 att visa. Den nya museimiljön ligger mycket långt ifrån den miljö som konstverken har tillkommit i. Konstnärsateljén är ofta en smutsig verkstad och konstnären själv är en fattig och underbetald innovatör som endast $\mathrm{i}$ undantagsfall kan leva på sitt verk. Museerna får här rollen av filter mellan två världar, den verkliga och den immateriella, på samma sätt som flygplatsbyggnaden med sin overkliga miljö är ett filter mellan vardagen och den fysiska tidsresan. Detta är det kanske viktigaste skälet till att konstnärer ofta föredrar helt andra miljöer för sina utställningar, bl.a. gamla fabriksmiljöer och "glömda platser".

En annan motsägelsefullhet $\mathrm{i}$ fråga om museet handlar inte bara om konstmuseet utan även om det kulturhistoriska museet. Det rör ordnandet av samlingarna, ofta i basutställningar, där man bygger upp en tidsaxel och väljer ett antal representativa situationer och objekt att representera denna. Allt kronologiskt ordnande handlar naturligtvis om ett val, och varje tid gör sitt eget val, vilket skulle omöjliggöra en mer permanent museiutställning. Det handlar i de flesta av museernas basutställningar om "a false continuity», om ett välvilligt tillrättaläggande av tiden och dess avlagringar som i grunden inte kan stå som någon sanning.

Samtidigt som samhället således allt mer känner behovet av det «minne» som museet innebär och satsar stora offentliga medel på att upprätta dessa, så framstår museernas basutställningar som alltmer tvivelaktiga verktyg. Den enda sanning de har möjlighet att föra fram är den om själva ordnandet och skälen bakom detta, inte om det innehåll de förmodas visa fram. Det gör nu kanske inte så mycket. All kunskap är fragmentariserad och måste fästas vid bräckliga fästen $\mathrm{i}$ form av subjektiva urval etc. Det är där basutställningen sprider falska utsagor. Det finns ingen bas, bara olika tolkningar av det kontinuum som vi kallat historien.

\section{RESAN OCH DEN TIDSSKYDDADE ZONEN}

Det finns en rörelse i vår tid som outtröttligt driver frågan om nya museer vidare. Det är inte en rörelse i vanlig bemärkelse, snarare en tendens, där såväl allmänhet som politiker och kulturverksamma alla agerar på sina respektive plan, och det handlar om inrättandet av museer för att skapa det som kunde kallas tidsskyddade zoner.

Dessa museiprojekt rör ofta individer, konstnärer, författare och andra som haft en historisk roll av något slag och som lämnat efter sig material i fysisk och andlig form som man anser bör bevaras åt eftervärlden. Materialet och museiidén är ofta knuten till en speciell lokal, kanske till den autentiska miljö där personen har levat och verkat. I Sverige har man t.ex. länge diskuterat ett Nobelmuseum, och konstnärer från 1900-talet, som målarna Sven X:et Erixson och Evert Lundquist, är exempel på personer som förknippats med museiprojekt - i det senare fallet också förverkligat $\mathrm{i}$ hans gamla ateljé i Drottningholm utanför Stockholm.

Det förekommer också talrika aktioner där medborgare kämpar för att skapa museer av gamla skolmiljöer eller av andra autentiska miljöer som ligger i riskzonen för att förstöras av vanvård eller ombyggnadsplaner. Det finns helt enkelt hos de flesta människor en stark drift att vilja bevara värdefulla kulturminnen åt historien och försöka skapa just tidsskyddade 


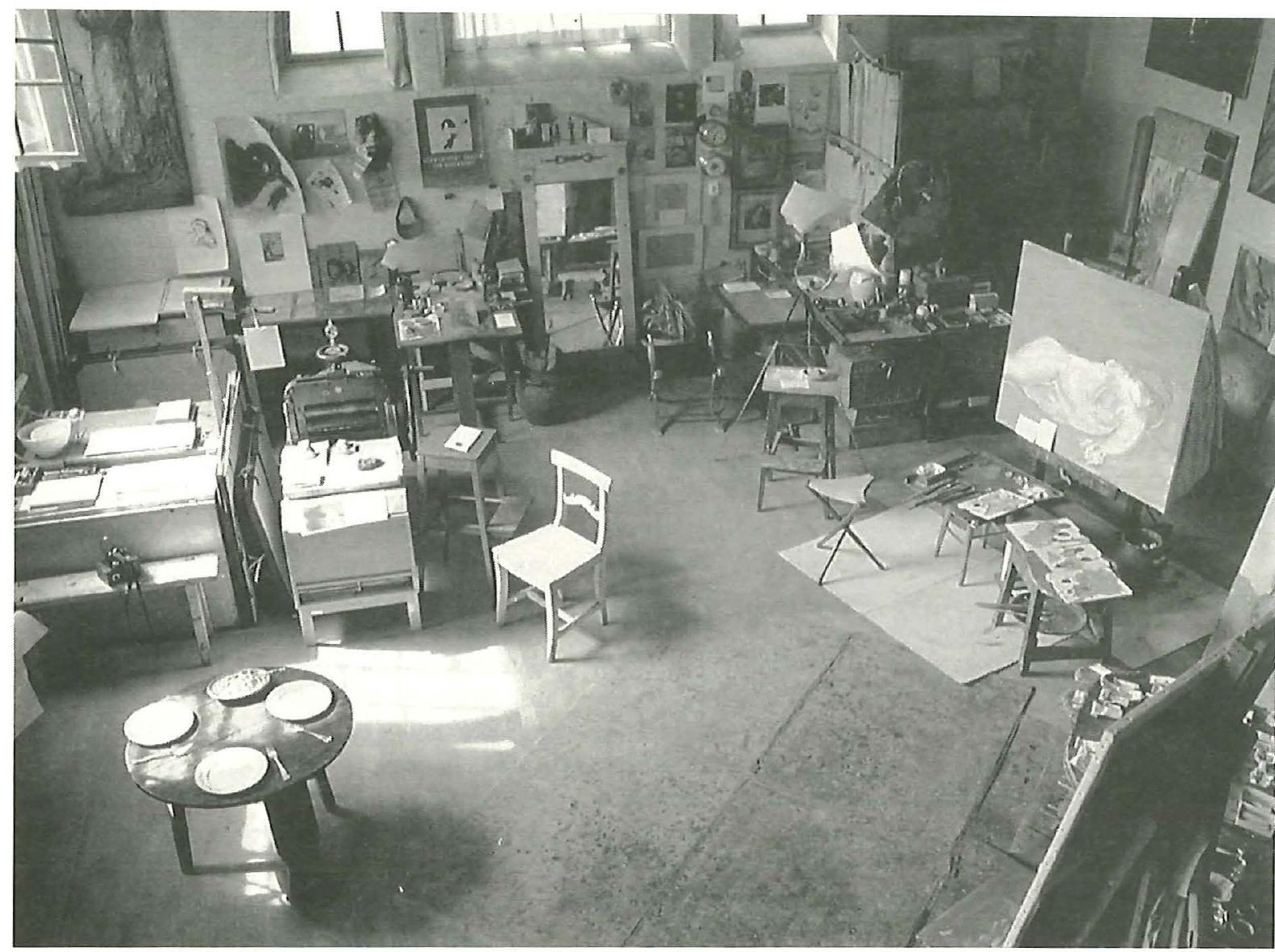

Evert Lundquists ateljé på Drottningholm.

zoner mitt i vardagen. Där håller museet på att få en förstärkt roll som verktyg undan förintelsen, och detta sker ofta $\mathrm{i}$ relativt begränsad skala i varje enskilt fall. Det är inte det stora monumentala museet man vill skapa. Det handlar snarare om att "spränga in" dessa zoner i samhällskroppen där de en gång hört hemma. Museet blir till en resa $\mathrm{i}$ tiden som får betydelse genom sitt autentiska djup mer än genom sin storlek och övergripande representativitet.

Sammanfattningsvis kan man således våga påstå, att vi har åtminstone två rörelser när det gäller museer i vår tid som verkar $\mathrm{i}$ en annan riktning än det vanliga konst- eller kulturhistoriska museet. Den ena handlar om att konsten i sin egen process misstror såväl den historiska ackumulationen som den fysiska ramen för den traditionella utställningen. Den andra accentuerar behovet av att plombera autentiska miljöer och skapandegärningar i mindre enheter som en form av zoner räddade undan tiden. Dessa utgör inget egentligt hot mot de existerande stora museikomplexen, men kan mycket tydligt förändra synen på utställningarnas roll inom museerna samt på förvärv och urvalsprocesser.

Idén med museet som tidsskyddad zon kan få en ideologiskt mer eller mindre tydlig form. Kanske är det så att vår tids speciella förkärlek för denna museiform har att göra med en allmän misstro mot det retoriska språket i de gamla konst- och kulturhistoriska museerna, som de flesta formades för nära nog ett sekel sedan. Det skulle betyda att dessa, dvs. vår tids nya museer, egentligen inte skulle vara användbara som politiska redskap, eftersom de tagit avstånd från alla former av tillrättaläggande och retorik.

I så fall är det viktigt att komma ihåg att museernas värld är en motsägelsefull värld, 
130 där vanor, traditioner och ideologier ligger som kålblad på varandra, och att vägen framåt är lika krokig som någonsin. Man kan nämligen också se en tendens i världens museiliv som går mot en förstärkning av museets roll $\mathrm{i}$ en politiskt ideologisk riktning, och där särskilt etniska frågor blivit fundamentet som man verkar utifrån. Detta gäller också konsten, och exemplen där är många, inte minst i USA. Frågor som rör etnicitet, tolkningsföreträde och kulturarv kommer att växa i betydelse i de delar av världen där folkomflyttningar, krig och etniska konflikter är omfattande, och dessa leder snarare tillbaka till en museiform, där makten över tolkningen av det kulturhistoriska materialet innehas av dem som också har den politiska makten.

Om man inser att en sådan utveckling är ofrånkomlig, blir behovet av att upprätta skyddade tidszoner kring konstnärer, livsformer och miljöer ännu viktigare. Där de finns $\mathrm{i}$ världen har de visat sig ha en betydelse långt utöver sin storlek och omfattning. Man kan ta som exempel Frida Kahlos blå hus i Coyoacán i Mexico City, som var hennes barndomshem samt hennes och Diego Rivieras bostad och som nu är Museo Frida Kahlo - ett av världens vackraste och märkligaste museer över en konstnär och hennes miljö. På samma sätt kan man idag i Rodinmuseet i Paris komma nära en av konsthistoriens intressantaste skulptörer, som knappast skulle få den utställningsytan i ett regelrätt museum för modern konst. Det traditionella konstmuseet är ingen neutral dokumentationsform - det är ett tolkningsverktyg med allt vad detta kan innebära av värderingar, missförstånd och tillrättalägganden.

\section{SUMMARY}

The Art Museum as Metaphor

Beate Sydhoff, art historian and writer, explores the role of the art museum as a metaphor for an idea and a period in history, something that has developed during the last thirty years. During this time the museum has become less representative and more subjective in terms of collections, less objective and more individualistic in its architecture and evidently more of a symbol than a functional construction housing historic remains.

Since the museum has a spiritual purpose but has to combine this with a physical construction, it may be possible - in many new museum buildings - also to see inspiration coming from airport terminals, - big transparent structures where the idea of transportation is brought forward in translucent and daring shapes. To discover art is also a kind of voyage, a movement in time and space that might be compared to travel in the physical sense.

One of the most interesting roles of the museum in our time, however, is to create zones, protected from the changes of time. Therefore, museums nowadays are often created out of existing environments, e.g. artists' studios or other kinds of unique spaces. One example of this kind is the house of the painter Frida Kahlo in Coyoacán in Mexico City. This place, Museo Frida Kahlo, could be seen as one of the most fascinating museums existing today, with its traces of Frida's life and artistic work, very much alive and in evidencce.

Beate Sydhoff är konsthistoriker, forfattare och kritiker. För närvarande programdirektör för EU-projektet Stockholm - Europas kulturhuvudstad 1998. Ordforande i den svenska nationella ICOM-komittén samt ordforrande i den regionala Europagruppen inom ICOM. Adr: Stockholm - Cultural Capital of Europe 1998 Sergels Torg 12, Box 7313, S-10390 Stockholm Fax: +46-8-249916 